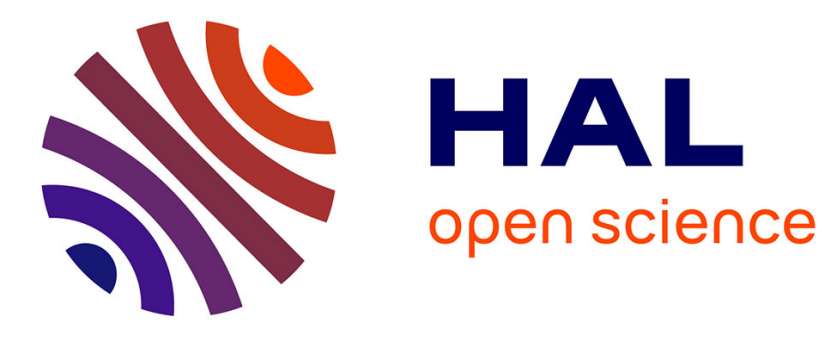

\title{
Implications of overweight in gastric cancer: a multicenter study in a Western patient population
}

J. Kulig, M. Sierzega, P. Kolodziejczyk, J. Dadan, M. Drews, M. Fraczek, A. Jeziorski, M. Krawczyk, T. Starzynska, G. Wallner

\section{- To cite this version:}

J. Kulig, M. Sierzega, P. Kolodziejczyk, J. Dadan, M. Drews, et al.. Implications of overweight in gastric cancer: a multicenter study in a Western patient population. EJSO - European Journal of Surgical Oncology, 2010, 36 (10), pp.969. 10.1016/j.ejso.2010.07.007 . hal-00625558

\section{HAL Id: hal-00625558 https://hal.science/hal-00625558}

Submitted on 22 Sep 2011

HAL is a multi-disciplinary open access archive for the deposit and dissemination of scientific research documents, whether they are published or not. The documents may come from teaching and research institutions in France or abroad, or from public or private research centers.
L'archive ouverte pluridisciplinaire HAL, est destinée au dépôt et à la diffusion de documents scientifiques de niveau recherche, publiés ou non, émanant des établissements d'enseignement et de recherche français ou étrangers, des laboratoires publics ou privés. 


\section{Accepted Manuscript}

Title: Implications of overweight in gastric cancer: a multicenter study in a Western patient population

Authors: J. Kulig, M. Sierzega, P. Kolodziejczyk, J. Dadan, M. Drews, M. Fraczek, A. Jeziorski, M. Krawczyk, T. Starzynska, G. Wallner

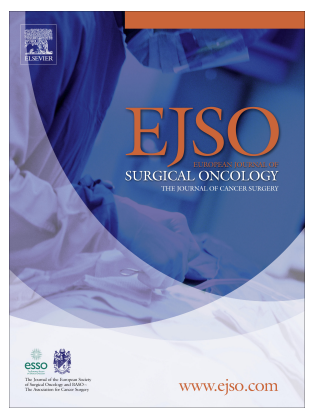

PII:

S0748-7983(10)00312-4

DOI:

10.1016/j.ejso.2010.07.007

Reference: YEJSO 3025

To appear in: European Journal of Surgical Oncology

Received Date: 18 March 2010

Revised Date: 10 July 2010

Accepted Date: 19 July 2010

Please cite this article as: Kulig J, Sierzega M, Kolodziejczyk P, Dadan J, Drews M, Fraczek M, Jeziorski A, Krawczyk M, Starzynska T, Wallner G. Implications of overweight in gastric cancer: a multicenter study in a Western patient population, European Journal of Surgical Oncology (2010), doi: 10.1016/ j.ejso.2010.07.007

This is a PDF file of an unedited manuscript that has been accepted for publication. As a service to our customers we are providing this early version of the manuscript. The manuscript will undergo copyediting, typesetting, and review of the resulting proof before it is published in its final form. Please note that during the production process errors may be discovered which could affect the content, and all legal disclaimers that apply to the journal pertain. 
Title: Implications of overweight in gastric cancer: a multicenter study in a Western patient population

Short Title: Overweight and prognosis in gastric cancer

Article type: Original research article

Authors: J. Kulig ${ }^{\text {a, }}$, M. Sierzega ${ }^{\text {a }}$, P. Kolodziejczyk ${ }^{\text {a }}$, J. Dadan ${ }^{\text {b }}$, M. Drews ${ }^{\text {c }}$, M. Fraczek ${ }^{\text {d }}$, A. Jeziorski ${ }^{\text {e }}$, M. Krawczyk ${ }^{\text {d, }}$ T. Starzynska ${ }^{\mathrm{f}}$, G. Wallner ${ }^{\mathrm{g}}$ on behalf of the Polish Gastric Cancer Study Group

\section{Authors' affiliation:}

${ }^{\mathrm{a}} 1^{\text {st }}$ Department of Surgery, Jagiellonian University Medical College, Krakow, Poland

${ }^{\mathrm{b}}$ Department of General and Endocrine Surgery, Medical University of Bialystok, Bialystok, Poland

${ }^{\mathrm{c}}$ Department of General, Gastroenterological and Endocrine Surgery, Poznan University of Medical Sciences, Poznan, Poland

${ }^{\mathrm{d}}$ Department of General, Transplant and Liver Surgery, Medical University of Warsaw, Warsaw, Poland

${ }^{\mathrm{e}}$ Department of Surgical Oncology, Medical University of Lodz, Lodz, Poland

${ }^{\mathrm{f}}$ Department of Gastroenterology, Pomeranian Medical Academy, Szczecin, Poland

${ }^{\mathrm{g}}$ II Department of General Surgery, Medical University of Lublin, Lublin, Poland

*Address for correspondence and reprints: Jan Kulig MD, $\mathrm{PhD}$,

$1^{\text {st }}$ Department of Surgery, 40 Kopernika Street,

31-501 Krakow, Poland, Phone/Facsimile: (48) 12-424-80-07,

e-mail: mskulig@cyf-kr.edu.pl

Keywords: gastric cancer; overweight; body mass index; lymph node dissection; prognosis; postoperative complications 


\section{ABSTRACT}

AIMS: The purpose of this study was to evaluate the effects of overweight on surgical and long-term outcomes in a Western population of patients with gastric cancer (GC).

METHODS: An electronic database of all patients with resectable GC treated between 1986 and 1998 at seven university surgical centres cooperating in the Polish Gastric Cancer Study Group was reviewed. Overweight was defined as a body mass index (BMI) of $25 \mathrm{~kg} / \mathrm{m}^{2}$ or higher.

RESULTS: Four hundred and ninety-two of 1992 (25\%) patients were overweight.

Postoperatively, higher BMI was associated with higher rates of cardiopulmonary complications ( $16 \%$ vs $12 \%, \mathrm{P}=0.001)$ and intra-abdominal abscess $(6.9 \%$ vs $2.9 \%, \mathrm{P}<0.001)$. However, other complications and mortality rates were unaffected. The median diseasespecific survival of overweight patients was significantly higher (36.7 months, 95\% confidence interval (CI) 29.0 to 44.4$)$ than those with BMI $<25 \mathrm{~kg} / \mathrm{m}^{2}(25.7$ months, $95 \% \mathrm{CI}$ 23.2 to $28.1 ; \mathrm{P}=0.003)$. These differences were due to the lower frequencies of patients with T3 and T4 tumours, metastatic lymph nodes, distant metastases, and non-curative resections. A Cox proportional hazards model identified age, depth of infiltration, lymph node metastases, distant metastases, and residual tumour category as the independent prognostic factors.

CONCLUSIONS: Overweight is not the independent prognostic factor for long-term survival in a Western-type population of GC. 


\section{INTRODUCTION}

Obesity is gaining increasing attention in surgical oncology. This is partially due to the recent epidemiological data suggesting that excess body weight is associated with an increased risk of various gastrointestinal malignancies, including gastric cancer, and particularly oesophagogastric adenocarcinomas. ${ }^{1,2}$ Moreover, from the surgical point of view, overweight patients are also exposed to a greater risk of interventions due to obesity-related comorbidities and increased incidence of postoperative complications. Another important aspect is related to some previous studies suggesting that overweight may influence the oncological outcomes of patients with gastrointestinal cancers. ${ }^{3,4}$

Several authors have already reported that overweight increases the incidence of general and intra-abdominal complications in Asian patients undergoing gastrectomy for gastric cancer. ${ }^{5-}$ ${ }^{12}$ Some recent studies also suggested that obesity may correlate with long-term prognosis..$^{9,13,}$

${ }^{14}$ However, as the prevalence of obesity is one of the principal differences between Western and Japanese or Korean patients with gastric cancer, influencing surgical technique and staging, simple approximation of observations reported from Asian populations is biased. ${ }^{15,16}$ This is particularly important for lymphadenectomy, as excess abdominal fat may markedly impair lymph node dissection and can play an important role in explaining the differences in surgical outcomes between Western and Asian patients. Surprisingly, data for the association between overweight and long-term outcomes outside of Japan and Korea is scarce. Moreover, the paucity of studies concerning Western populations and potential flaws in reports from single institutions or including only a limited number of patients preclude a reliable evaluation of existing data. ${ }^{17-19}$ 
The aim of this study was to examine the relationship between overweight and long-term survival of patients undergoing gastrectomy for gastric cancer and to evaluate the potential mechanisms underlying these effects in terms of postoperative complications and adequacy of surgical therapy. 


\section{METHODS}

\section{Patient selection}

An electronic database of all patients with resectable gastric cancer treated between 1986 and 1998 at seven university surgical centres participating in the Polish Gastric Cancer Study Group (PGCSG) was reviewed. All relevant data, including demographics, clinical findings, details of surgical procedures and histopathological parameters, were collected prospectively using standard forms. Overweight was defined according to the World Health Organization classification as a body mass index (BMI) of $25 \mathrm{~kg} / \mathrm{m}^{2}$ or higher. ${ }^{20}$ This study was approved by the Bioethics Committees at each institution.

\section{Treatment and follow-up}

The type of stomach resection was selected based on tumour location and was not influenced by patients' BMI. In general, a subtotal gastrectomy with Billroth II reconstruction was used for tumours of the distal and some middle stomach. Proximal gastric cancer without gross involvement of surrounding tissues was treated with a proximal subtotal gastrectomy and oesophagogastric anastomosis. Total gastrectomy with Roux-en-Y reconstruction was typically used in other cases. Primary tumours were resected en bloc with perigastric lymph nodes (groups 1-6 according to the Japanese Gastric Cancer Association (JGCA)), whereas extragastric nodal stations (groups 7-11 and/or 7-12, depending on the site of the primary tumour) were dissected separately. The extent of lymphadenectomy was described by the operating surgeon and finally evaluated by the pathologist by counting resected lymph nodes in individual stations as defined by the JGCA. Lymph nodes were identified and retrieved from surgical specimens without using any specific technique to increase nodal retrieval rate. Paraffin-embedded nodes were stained with haematoxylin and eosin, and examined microscopically for metastases. No special immunohistochemical techniques were used to 
identify micrometastases. Follow-up data were collected based on clinical examination every 3-6 months after discharge and dates of death were verified using data obtained from the census registry office. Survival rates were calculated based on the disease-specific principle, i.e. deaths due to gastric cancer were accepted as complete observations, while death due to other reasons and lost to follow-up was considered as a censored observation.

\section{Statistical methods}

Mann-Whitney $U$ and $\chi^{2}$ tests were used where appropriate to compare the distribution of individual variables between groups. Survival data was analysed according to the KaplanMeier method and included postoperative mortality; the log rank test was used to detect differences between groups. Multivariable analysis was performed using a Cox proportional hazards model with a backward stepwise selection procedure. The probability for entering the model was 0.050 and that for removal from the model was $0.100 . P<0.050$ was considered statistically significant. Statistical analysis was performed using the SPSS $^{\circledR}$ version 16 software package (SPSS, Chicago, Illinois, USA). 


\section{RESULTS}

\section{Demographic data}

Between 1986 and 1998, 1992 records with detailed information regarding patient-related and tumour-related variables, including body height and body weight, were identified in the PGCSG database. The median BMI was 22.7 (range 15 to 39) and 492 patients had BMI of 25 $\mathrm{kg} / \mathrm{m}^{2}$ or more. Table 1 shows clinico-pathological features of the analysed population. Compared to patients with BMI $<25 \mathrm{~kg} / \mathrm{m}^{2}$, overweight was associated with a slightly higher incidence of cardiocirculatory disorders and a significantly higher rate of diabetes mellitus.

\section{Surgery}

No significant differences were observed with respect to the type of gastrectomy, extent of lymphadenectomy, and the proportion of patients undergoing pancreaticosplenectomy. There was a negative linear correlation between BMI and the number of dissected lymph nodes with a correlation coefficient $\mathrm{r}=-0.072(\mathrm{P}=0.002)$. Overweight patients had a higher proportion of cases with 15 or less nodes in the surgical specimen ( $45 \%$ vs $37 \%, \mathrm{P}=0.002$ ) and the correlation between this proportion and BMI was highly significant $(r=0.759$, $\mathrm{P}<0.001)$. The overall mean number of removed lymph nodes in our series was lower than currently accepted as a standard, but most patients analysed in this study were operated on before 1995, when a policy of routine extent of lymphadenectomy of at least D2 was implemented. Moreover, a limited lymph node dissection was generally performed in all patients with synchronous distant metastases. The following variables were tested by logistic regression analysis to identify those associated with an inadequate number (i.e. 15 or less) of dissected lymph nodes: patient age $(<40,40-65,>65$ years), sex, BMI (continuous variable), tumour location (upper, middle, distal third, whole stomach), Lauren's type, depth of wall penetration (T category), nodal status (positive or negative), distant metastases (present, 
absent), type of surgical resection, pancreaticosplenectomy, and extent of lymphadenectomy. D1 lymphadenectomy (Odds Ratio (OR) 4.16, 95\%CI 3.12 to 5.54, P<0.001), absence of lymph node metastases (OR $2.13,95 \%$ CI 1.64 to $2.75, \mathrm{P}<0.001$ ), tumours limited to the gastric mucosa and submucosa (OR 1.57, 95\%CI 1.05 to $2.35, \mathrm{P}=0.027)$, and $\mathrm{BMI}$ (OR 1.03, 95\%CI 1.01 to $1.07, \mathrm{P}=0.033$ ) were independent predictors of low lymph node count in surgical specimens.

\section{Pathology}

The anatomical distribution of tumours within the stomach and the proportion of individual Lauren's types were similar between groups. Overweight patients had a significantly lower proportion of category $\mathrm{T} 3$ and $\mathrm{T} 4$ tumours $(64 \%$ vs $71 \%, \mathrm{P}=0.005)$ and the prevalence of synchronous distant metastases. Moreover, patients with a BMI below $25 \mathrm{~kg} / \mathrm{m}^{2}$ were significantly more likely to undergo non-curative resection.

Overweight was associated with a lower proportion of patients with metastatic lymph nodes (59\% vs $70 \%, \mathrm{P}<0.001)$ and a lower median ratio of metastatic/resected lymph nodes $(0.17$ vs $0.30, \mathrm{P}=0.003$ ). For both of these parameters there was a significant negative linear correlation with BMI and corresponding Pearson's coefficients of regression were -0.730 $(\mathrm{P}=0.003)$ and $-0.075(\mathrm{P}=0.007)$, respectively. However, if 16 or more lymph nodes were dissected, the proportion of patients with individual $\mathrm{N}$ categories was unaffected by BMI and there was no correlation between BMI and the prevalence of metastatic lymph nodes or the ratio of metastatic/resected lymph nodes.

\section{Postoperative course}

Postoperative recovery was uneventful in 1277 patients and morbidity rates for overall complications were similar regardless of BMI (Tab. 2). Overweight was associated with 
significantly higher rates of cardiopulmonary complications ( $16 \%$ vs $12 \%, \mathrm{P}=0.010)$ and intra-abdominal abscess $(6.9 \%$ vs $2.9 \%, \mathrm{P}<0.001)$. Other complications and mortality rates were not influenced by BMI. The median postoperative stay was longer in overweight subjects (17 vs 14 days, $\mathrm{P}<0.001)$.

\section{Long-term survival}

At the time of final follow-up (December 2006), 1295 of 1992 patients had died, and the median follow-up period for surviving subjects was 104 months. The median disease-specific survival of overweight patients was significantly higher (36.7 months, 95\%CI 29.0 to 44.4) than those with $\mathrm{BMI}<25 \mathrm{~kg} / \mathrm{m}^{2}$ (25.7 months, 95\%CI 23.2 to $28.1 ; \mathrm{P}=0.003$ ) (Fig. 1). To explain these differences, survival rates between overweight and non-overweight patients were compared after stratification based on tumour staging. Since Kaplan-Meier's curves for groups with BMI $<25 \mathrm{~kg} / \mathrm{m}^{2}$ and $\geq 25 \mathrm{~kg} / \mathrm{m}^{2}$ superimposed on stages I-II and III-IV (Fig.2AB), survival benefits of overweight were related to the differences in tumour staging. A Cox proportional hazards model was constructed including variables that significantly affected disease-specific survival in the univariate analysis, i.e. age $(<40,40-65,>65$ years $)$, BMI ( $<25 \mathrm{~kg} / \mathrm{m}^{2}, \geq 25 \mathrm{~kg} / \mathrm{m}^{2}$ ), tumour location (upper, middle or distal third, whole stomach), Laurén's classification (intestinal, diffuse, mixed), depth of infiltration (T1-T4), nodal status (N0-Nx), metastatic/resected lymph node ratio $(0,0-20 \%,>20 \%)$, distant metastases (no, yes), potentially curative resection (no, yes), splenectomy (no, yes), and postoperative chemotherapy (no, yes). The only independent prognostic factors were age, depth of infiltration, lymph node metastases, metastatic/resected lymph node ratio, distant metastases, and residual tumour category (Tab. 3). The hazard ratio in overweight patients compared to those with BMI $<25 \mathrm{~kg} / \mathrm{m}^{2}$ was 0.89 (95\% CI 0.77 to $1.04, \mathrm{P}=0.139$ ). Considering the differences observed among tumour stages, two additional Cox models were constructed for 
stages IA through II and separately IIIA through IV. Nevertheless, overweight was not a significant predictor of survival with hazard ratios of 0.940 (95\%CI 0.703 to $1.257, \mathrm{P}=0.667$ ) and 0.916 (95\%CI 0.777 to $1.079, \mathrm{P}=0.292)$, respectively. Similar results were obtained if the model was stratified for curative and non-curative resections. 


\section{DISCUSSION}

\section{The influence of overweight on survival}

One of the major clinical differences between patients with gastric cancer in the West and those in Japan or Korea is a much higher prevalence of overweight and obesity that may have important practical consequences. The most important aspect is related to findings from Japanese populations suggesting that obesity may correlate with long-term prognosis of gastric carcinoma. Tokunaga et al. ${ }^{14}$ presented the largest analysis to date evaluating the correlation of BMI and long-term survival in 7925 patients treated with curative intent in a Japanese centre. Unexpectedly, the 5-year survival rate of $84.0 \%$ in overweight patients (BMI $\left.\geq 25 \mathrm{~kg} / \mathrm{m}^{2} ; \mathrm{n}=1126\right)$ was significantly higher $(\mathrm{P}<0.001)$ than $76.7 \%$ in the non-obese group (BMI $\left.<25 \mathrm{~kg} / \mathrm{m}^{2} ; \mathrm{n}=6799\right)$. Moreover, multivariate analysis of potential prognostic factors demonstrated that higher BMI significantly reduced the risk of death (hazard ratio 0.874 , 95\%CI 0.773-0.988, P=0.032). Despite these results, prognostic implications of overweight are not well established for gastric cancer as smaller Japanese studies demonstrated that high BMI was an independent predictor of recurrence ${ }^{9}$ or questioned its influence on the long-term outcomes. ${ }^{8,10,12,21}$ Similarly, the definitive implications of overweight in Western patients with gastric cancer have yet to be determined due to the paucity of data for the association between BMI and prognosis. $^{22}$

Using a well defined multi-institutional data set from a Western country, the present study demonstrated that overweight was associated with a significant survival benefit by univariate analysis. However, unlike Tokunaga et al., ${ }^{14} \mathrm{BMI} \geq 25 \mathrm{~kg} / \mathrm{m}^{2}$ was not an independent prognostic factor, suggesting that other covariates are responsible for such findings. The three most relevant aspects of overweight that may influence patients' survival are the relationship 
between BMI and postoperative morality, tumour staging, and adequacy of surgical therapy, discussed below.

\section{Correlation of BMI with postoperative complications}

Most previous retrospective studies from Asian populations suggest that BMI influences the occurrence of surgical complications in gastric cancer surgery indirectly by increasing operation time ${ }^{8-10,12}$ and blood loss ${ }^{8-10,23}$, but also directly increasing rates of pancreatic fistula ${ }^{6-8}$ and abdominal abscess. ${ }^{8,24}$ Moreover, these observations are supported by the results of randomized clinical trials confirming the detrimental effects of overweight. ${ }^{5,25}$ Although some reports from Western populations revealed that BMI was not a significant predictor of postoperative morbidity ${ }^{18,19}$, the present findings strongly suggest that overweight may significantly contribute to the early postoperative outcomes. However, as in other reports, high BMI did not increase mortality rates, and thus cannot be responsible for the marked differences in long-term survival rates.

\section{Implications of overweight for lymph node dissection}

Inadequate lymph node dissection during gastrectomy could be another factor potentially worsening a patients' prognosis, as excess fat may limit accessibility to lymph nodes located deep in the adipose tissue around major abdominal vessels not included in the routine en block resection. Such assumptions are based on several observations concerning the different extent of lymphadenectomy. ${ }^{5,9,21,23}$ However, previous reports from Western population-based databases and randomized clinical trials provided no data on the influence of BMI on the likelihood of undergoing adequate lymph node assessment. ${ }^{15,26-29}$ In the present study, BMI significantly affected the proportion of patients with 15 or less lymph nodes removed and after stratifying patients for the extent of lymphadenectomy, this effect was preserved for both 
D1 and D2 dissection. As several reports emphasised the importance of the stage migration phenomenon and poorer prognosis related to inadequate lymph node dissection, including our series (hazard ratio for $\mathrm{Nx} 1.85,95 \% \mathrm{CI} 1.48$ to $2.32, \mathrm{P}<0.001$ ), this observation has important clinical implications for surgeons operating obese individuals.

\section{Impact of BMI on tumour staging}

Staging differences related to BMI may be another potential factor responsible for discrepancies in long-term survival between overweight and non-overweight patients. Present findings suggest that high BMI is associated with markedly reduced proportions of tumours infiltrating gastric serosa, surrounding organs, metastatic lymph nodes, and distant metastases. As these variables are most commonly reported as independent prognostic factors for gastric cancer, the most likely explanation of better long-term survival found in the univariate analysis for overweight in our population is the correlation between BMI and tumour staging. This hypothesis is confirmed by the Kaplan-Meier's plots and Cox's proportional hazards models stratified for the American Joint Committee on Cancer (AJCC) stage (Fig.2A-B). Data collected in a Japanese cohort of 7925 patients suggested a similar conclusion that the prevalence of T3-4 and N2-3 cancers decreases significantly in patients with BMI $\geq 25$ $\mathrm{kg} / \mathrm{m}^{2} \cdot{ }^{14}$ Nevertheless, these correlations should be further validated with population-based databases since some studies involving smaller Asian populations failed to confirm any association between BMI and staging. ${ }^{8,10,12}$ Moreover, the mechanism of such less aggressive behaviour of gastric cancer in overweight individuals is yet to be determined, as some previous studies in hormone-dependent cancers (breast and prostate) and colorectal cancer reported a positive correlation between BMI and cancer stages, unlike the results of this study. $^{30}$ 


\section{Conclusion}

The present study provided for the first time data for the association between BMI and prognosis of gastric cancer from a large-scale Western-type population. Although higher BMI increased rates of some postoperative complications and impaired adequacy of lymph node dissection, better survival rates observed in overweight patients were related to the higher proportion of less advanced tumours. Therefore, overweight was not an independent prognostic factor for long-term survival. 


\section{AUTHORS' CONTRIBUTIONS}

Study concept and design: Kulig, Sierzega, Kolodziejczyk.

Acquisition of data: Dadan, Drews, Frączek, Jeziorski, Kolodziejczyk, Krawczyk, Sierzega, Starzynska, Wallner.

Analysis and interpretation of data: Sierzega, Kolodziejczyk.

Drafting of the manuscript: Sierzega, Kolodziejczyk.

Critical revision of the manuscript: Dadan, Drews, Frączek, Jeziorski, Krawczyk, Kulig, Starzynska, Wallner.

All authors had access to portions of the raw data corresponding to their investigational sites. Jan Kulig, Marek Sierzega, and Piotr Kolodziejczyk had access to all data in the study and analysis.

\section{CONFLICT OF INTEREST STATEMENTS}

The authors declare that they have no conflicts of interest.

\section{ETHICS COMMITTEE APPROVAL}

This study was approved by the Bioethics Committees at each institution.

\section{ROLE OF FUNDING SOURCE}

This study was financially supported by the Polish State Committee for Scientific Research, Grants no. 3 P05C 067 23p01, 2 P05C 024 29, 3 P05C 031 22, N403 069 31/3255

The funding source did not participate in study design, collection, analysis, or interpretation of the data, or writing of the report.

\section{ACKNOWLEDGMENT}

Other Members of the Polish Gastric Cancer Study Group: 
Roman Bandurski, Andrzej Dabrowski, Halina Jaroszewicz-Heigelmann, Krzysztof Marlicz, Wiktor Łaszewicz, Zbigniew Puchalski, Boleslaw Stawny, Antoni M. Szczepanik, Jaroslaw Szymczuk, Konrad Wronski 


\section{REFERENCES}

1. Renehan AG, Tyson M, Egger M, et al. Body-mass index and incidence of cancer: a systematic review and meta-analysis of prospective observational studies. Lancet 2008;371(9612): 569-578.

2. Yang P, Zhou Y, Chen B, et al. Overweight, obesity and gastric cancer risk: Results from a meta-analysis of cohort studies. Eur J Cancer 2009;45(16): 2867-2873.

3. You JF, Tang R, Changchien CR, et al. Effect of body mass index on the outcome of patients with rectal cancer receiving curative anterior resection: disparity between the upper and lower rectum. Ann Surg 2009;249(5): 783-787.

4. Moon HG, Ju YT, Jeong CY, et al. Visceral obesity may affect oncologic outcome in patients with colorectal cancer. Ann Surg Oncol 2008;15(7): 1918-1922.

5. Tsujinaka T, Sasako M, Yamamoto S, et al. Influence of overweight on surgical complications for gastric cancer: results from a randomized control trial comparing D2 and extended para-aortic D3 lymphadenectomy (JCOG9501). Ann Surg Oncol 2007;14(2): 355-361.

6. Kunisaki C, Shimada $\mathrm{H}$, Ono H, et al. Predictive factors for pancreatic fistula after pancreaticosplenectomy for advanced gastric cancer in the upper third of the stomach. $J$ Gastrointest Surg 2006;10(1): 132-137.

7. Tanaka K, Miyashiro I, Yano M, et al. Accumulation of excess visceral fat is a risk factor for pancreatic fistula formation after total gastrectomy. Ann Surg Oncol 2009;16(6): 1520-1525.

8. Ojima T, Iwahashi M, Nakamori M, et al. Influence of overweight on patients with gastric cancer after undergoing curative gastrectomy: an analysis of 689 consecutive cases managed by a single center. Arch Surg 2009;144(4): 351-358. 
9. Dhar DK, Kubota H, Tachibana M, et al. Body mass index determines the success of lymph node dissection and predicts the outcome of gastric carcinoma patients. Oncology 2000;59(1): 18-23.

10. Inagawa $\mathrm{S}$, Adachi $\mathrm{S}$, Oda $\mathrm{T}$, et al. Effect of fat volume on postoperative complications and survival rate after D2 dissection for gastric cancer. Gastric Cancer 2000;3(3): 141144.

11. Lee JH, Paik YH, Lee JS, et al. Abdominal shape of gastric cancer patients influences short-term surgical outcomes. Ann Surg Oncol 2007;14(4): 1288-1294.

12. Oh SJ, Hyung WJ, Li C, et al. Effect of being overweight on postoperative morbidity and long-term surgical outcomes in proximal gastric carcinoma. J Gastroenterol Hepatol 2009;24(3): 475-479.

13. Moriwaki Y, Kunisaki C, Kobayashi S, et al. Does body mass index (BMI) influence morbidity and long-term survival in gastric cancer patients after gastrectomy? Hepatogastroenterology 2003;50(49): 284-288.

14. Tokunaga M, Hiki N, Fukunaga T, et al. Better 5-year survival rate following curative gastrectomy in overweight patients. Ann Surg Oncol 2009;16(12): 3245-3251.

15. Bunt AM, Hermans J, van de Velde CJ, et al. Lymph node retrieval in a randomized trial on western-type versus Japanese-type surgery in gastric cancer. J Clin Oncol 1996;14(8): 2289-2294.

16. Davis PA, Sano T. The difference in gastric cancer between Japan, USA and Europe: what are the facts? what are the suggestions? Crit Rev Oncol Hematol 2001;40(1): 77-94.

17. Barry JD, Blackshaw GR, Edwards P, et al. Western body mass indices need not compromise outcomes after modified D2 gastrectomy for carcinoma. Gastric Cancer 2003;6(2): 80-85. 
18. Schumacher G, Schlechtweg N, Chopra SS, et al. Einfluss des Body-Mass-Index auf die Prognose und Komplikationsrate nach Resektion beim Kardiakarzinom. Zentralbl Chir 2009;134(1): 66-70.

19. Gretschel S, Christoph F, Bembenek A, et al. Body mass index does not affect systematic D2 lymph node dissection and postoperative morbidity in gastric cancer patients. Ann Surg Oncol 2003;10(4): 363-368.

20. Seidell JC, Flegal KM. Assessing obesity: classification and epidemiology. Br Med Bull 1997;53(2): 238-252.

21. Kodera Y, Ito S, Yamamura Y, et al. Obesity and outcome of distal gastrectomy with D2 lymphadenectomy for carcinoma. Hepatogastroenterology 2004;51(58): 1225-1228.

22. Trivers KF, De Roos AJ, Gammon MD, et al. Demographic and lifestyle predictors of survival in patients with esophageal or gastric cancers, Clin Gastroenterol Hepatol 2005;3(3): 225-230.

23. Hiki N, Fukunaga T, Yamaguchi T, et al. Increased fat content and body shape have little effect on the accuracy of lymph node retrieval and blood loss in laparoscopic distal gastrectomy for gastric cancer. J Gastrointest Surg 2009;13(4): 626-633.

24. Katai H, Yoshimura K, Fukagawa T, et al. Risk factors for pancreas-related abscess after total gastrectomy. Gastric Cancer 2005;8(3): 137-141.

25. Kodera Y, Sasako M, Yamamoto S, et al. Identification of risk factors for the development of complications following extended and superextended lymphadenectomies for gastric cancer. Br J Surg 2005;92(9): 1103-1109.

26. Coburn NG, Swallow CJ, Kiss A, et al. Significant regional variation in adequacy of lymph node assessment and survival in gastric cancer. Cancer 2006;107(9): 2143-2151.

27. Baxter NN, Tuttle TM. Inadequacy of lymph node staging in gastric cancer patients: a population-based study. Ann Surg Oncol 2005;12(12): 981-987. 
28. Bouvier AM, Haas O, Piard F, et al. How many nodes must be examined to accurately stage gastric carcinomas? Results from a population based study. Cancer 2002;94(11): $2862-2866$.

29. Yang SH, Zhang YC, Yang KH, et al. An evidence-based medicine review of lymphadenectomy extent for gastric cancer. Am J Surg 2009;197(2): 246-251.

30. Calle EE, Thun MJ. Obesity and cancer. Oncogene 2004;23(38): 6365-6378. 


\section{TABLES}

Table 1. Clinico-pathological features of overweight $\left(\mathrm{BMI} \geq 25 \mathrm{~kg} / \mathrm{m}^{2}\right)$ and non-overweight $\left(\mathrm{BMI}<25 \mathrm{~kg} / \mathrm{m}^{2}\right)$ patients

\begin{tabular}{|c|c|c|c|}
\hline & $\begin{array}{l}\mathrm{BMI} \geq 25 \mathrm{~kg} / \mathrm{m}^{2} \\
(\mathrm{n}=492)\end{array}$ & $\begin{array}{l}\mathrm{BMI}<25 \mathrm{~kg} / \mathrm{m}^{2} \\
(\mathrm{n}=1500)\end{array}$ & $\mathrm{P}$ \\
\hline Gender & & & $0.510 \dagger$ \\
\hline female & 161 & 467 & \\
\hline male & 331 & 1033 & \\
\hline Age, yr (median (range)) & $59(18-85)$ & $60(19-85)$ & $0.298 \ddagger$ \\
\hline \multicolumn{4}{|l|}{ Co-morbidities } \\
\hline cardiocirculatory & 53 & 127 & $0.121 \dagger$ \\
\hline diabetes & 18 & 24 & $0.006 \dagger$ \\
\hline Tumour location & & & $0.126 \dagger$ \\
\hline upper & 74 & 250 & \\
\hline middle & 162 & 545 & \\
\hline distal & 94 & 287 & \\
\hline whole stomach & 162 & 418 & \\
\hline Laurén's classification & & & $0.955 \dagger$ \\
\hline intestinal & 266 & 824 & \\
\hline diffused & 170 & 509 & \\
\hline mixed & 56 & 167 & \\
\hline Depth of infiltration (AJCC 2002) & & & $0.042 \dagger$ \\
\hline $\mathrm{T} 1$ & 68 & 159 & \\
\hline $\mathrm{T} 2$ & 109 & 280 & \\
\hline $\mathrm{T} 3$ & 218 & 714 & \\
\hline $\mathrm{T} 4$ & 97 & 347 & \\
\hline
\end{tabular}




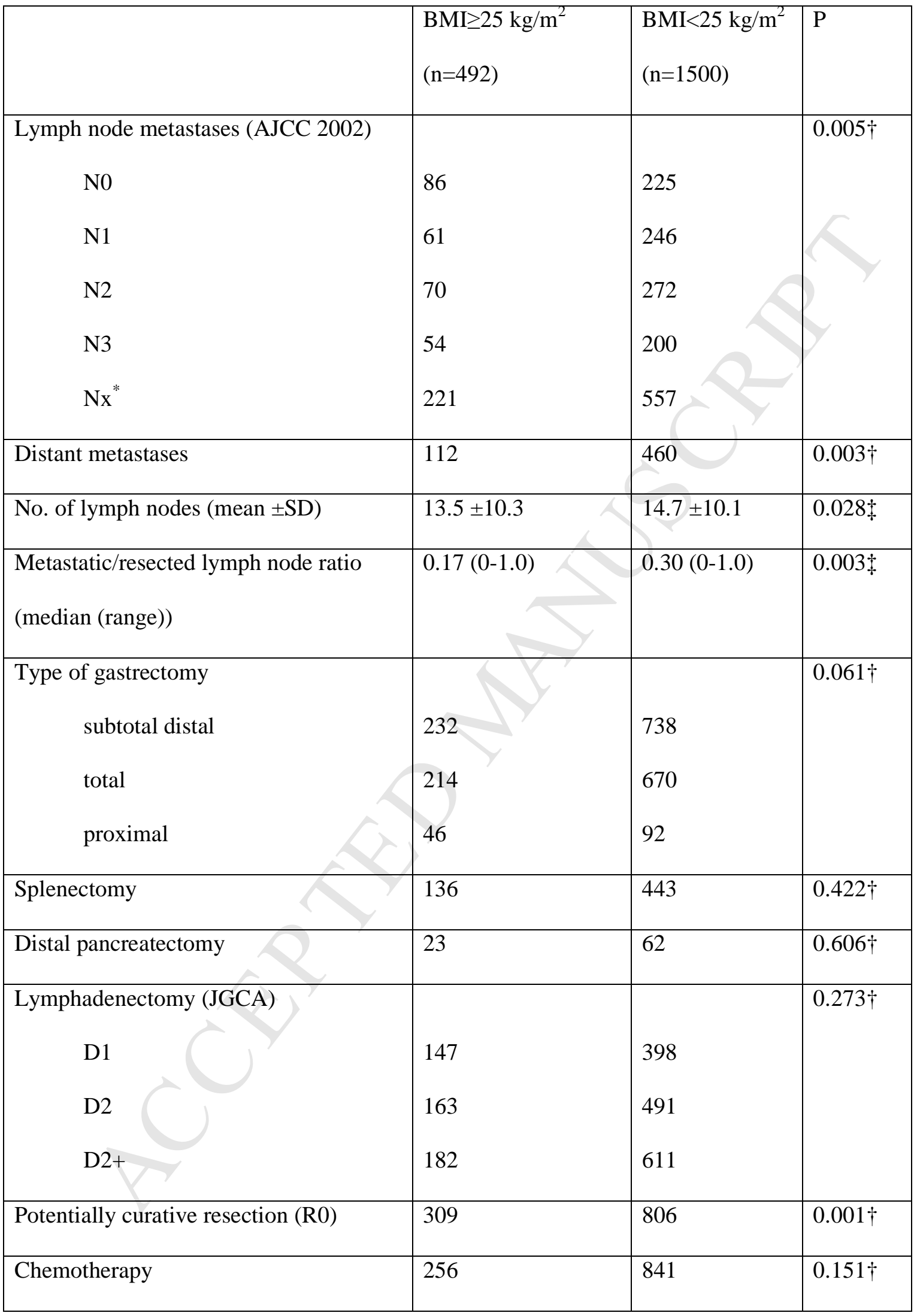


*15 or less lymph nodes removed; $†$ chi-square test; $\ddagger$ U Mann-Withney test; BMI - Body

Mass Index; AJCC - American Joint Committee on Cancer; JGCA - Japanese Gastric Cancer

Association 
Table 2. Postoperative complications according to BMI

\begin{tabular}{|l|l|l|l|}
\hline & $\begin{array}{l}\mathrm{BMI} \geq 25 \mathrm{~kg} / \mathrm{m}^{2} \\
(\mathrm{n}=492)\end{array}$ & $\begin{array}{l}\mathrm{BMI}<25 \mathrm{~kg} / \mathrm{m}^{2} \\
(\mathrm{n}=1500)\end{array}$ & \\
\hline Any complication & 182 & 533 & 0.558 \\
\hline Cardiopulmonary & 79 & 174 & 0.010 \\
\hline Anastomotic leakage & 17 & 36 & 0.206 \\
\hline Intra-abdominal abscess & 34 & 43 & $<0.001$ \\
\hline Intra-abdominal bleeding & 6 & 15 & 0.679 \\
\hline Wound infection & 19 & 46 & 0.389 \\
\hline Other & 15 & 60 & 0.306 \\
\hline Relaparotomy & 23 & 57 & 0.391 \\
\hline Mortality & 2 & 16 & 0.179 \\
\hline * chi-square test & & & \\
\hline
\end{tabular}




\section{ACCEPTED MANUSCRIPT}

Table 3. Multivariate analysis of independent prognostic factors for survival (Cox proportional hazards model)

\begin{tabular}{|c|c|c|c|}
\hline Parameter & Category & Hazard Ratio (95\%CI) & $P$ \\
\hline Age (years) & $\begin{array}{c}<40 \\
40-65 \\
>65\end{array}$ & $\begin{array}{c}1 \\
1.35(1.04-1.76) \\
1.69(1.26-2.27)\end{array}$ & $\begin{array}{c}0.024 \\
<0.001\end{array}$ \\
\hline BMI & $\begin{array}{l}<25 \mathrm{~kg} / \mathrm{m}^{2} \\
\geq 25 \mathrm{~kg} / \mathrm{m}^{2}\end{array}$ & $\begin{array}{c}1 \\
0.89(0.77-1.04)\end{array}$ & 0.139 \\
\hline Tumour location & $\begin{array}{l}\text { Distal } \\
\text { Middle } \\
\text { Upper } \\
\text { Whole }\end{array}$ & $\begin{array}{c}1 \\
0.99(0.87-1.21) \\
1.13(0.66-1.81) \\
1.16(0.62-2.15)\end{array}$ & $\begin{array}{l}0.881 \\
0.894 \\
0.647\end{array}$ \\
\hline Laurén's classification & $\begin{array}{l}\text { Intestinal } \\
\text { Diffuse } \\
\text { Mixed }\end{array}$ & $\begin{array}{c}1 \\
1.01(0.87-1.16) \\
1.02(0.84-1.25)\end{array}$ & $\begin{array}{l}0.932 \\
0.809\end{array}$ \\
\hline Splenectomy & $\begin{array}{l}\text { No } \\
\text { Yes }\end{array}$ & $\begin{array}{c}1 \\
1.09(0.95-1.26)\end{array}$ & 0.232 \\
\hline Depth of infiltration & $\begin{array}{l}\mathrm{T} 1 \\
\mathrm{~T} 2 \\
\mathrm{~T} 3 \\
\mathrm{~T} 4\end{array}$ & $\begin{array}{c}1 \\
1.94(1.35-2.78) \\
2.71(1.92-3.83) \\
3.33(2.28-4.88)\end{array}$ & $\begin{array}{l}<0.001 \\
<0.001 \\
<0.001\end{array}$ \\
\hline Lymph node metastases & $\begin{array}{l}\text { N0 } \\
\text { N1 } \\
\text { N2 } \\
\text { N3 } \\
\text { Nx }\end{array}$ & $\begin{array}{c}1 \\
1.32(0.96-1.81) \\
2.59(2.10-3.18) \\
3.54(2.75-4.56) \\
1.85(1.48-2.32)\end{array}$ & $\begin{aligned} & 0.085 \\
< & 0.001 \\
< & 0.001 \\
< & 0.001\end{aligned}$ \\
\hline Metastatic/resected lymph node ratio & $\begin{array}{c}0 \\
0-20 \% \\
>20 \%\end{array}$ & $\begin{array}{c}1 \\
1.45(1.07-1.97) \\
2.11(1.67-2.65)\end{array}$ & $\begin{array}{c}0.018 \\
<0.001\end{array}$ \\
\hline Distant metastases & $\begin{array}{l}\text { No } \\
\text { Yes }\end{array}$ & $\begin{array}{c}1 \\
1.37(1.13-1.66)\end{array}$ & 0.002 \\
\hline Residual tumour category & $\begin{array}{c}\text { R0 } \\
\text { R1 or R2 }\end{array}$ & $\begin{array}{c}1 \\
2.21(1.99-3.5)\end{array}$ & $<0.001$ \\
\hline
\end{tabular}




No

Yes

$0.96(0.83-1.11)$

0.583 


\section{FIGURE LEGENDS}

Fig. 1. Disease-specific survival for overweight $\left(\mathrm{BMI} \geq 25 \mathrm{~kg} / \mathrm{m}^{2}\right)$ and non-overweight (BMI $\left.<25 \mathrm{~kg} / \mathrm{m}^{2}\right)$ patients $(p=0.003, \log$-rank test $)$.

Fig. 2. Disease-specific survival for overweight $\left(\mathrm{BMI} \geq 25 \mathrm{~kg} / \mathrm{m}^{2}\right)$ and non-overweight (BMI $\left.<25 \mathrm{~kg} / \mathrm{m}^{2}\right)$ patients according to tumour stage. A. Stage I and II ( $p=0.960, \log -$ rank test $) ; \mathbf{B}$.

Stage III and IV $(p=0.229, \log$-rank test $)$ 


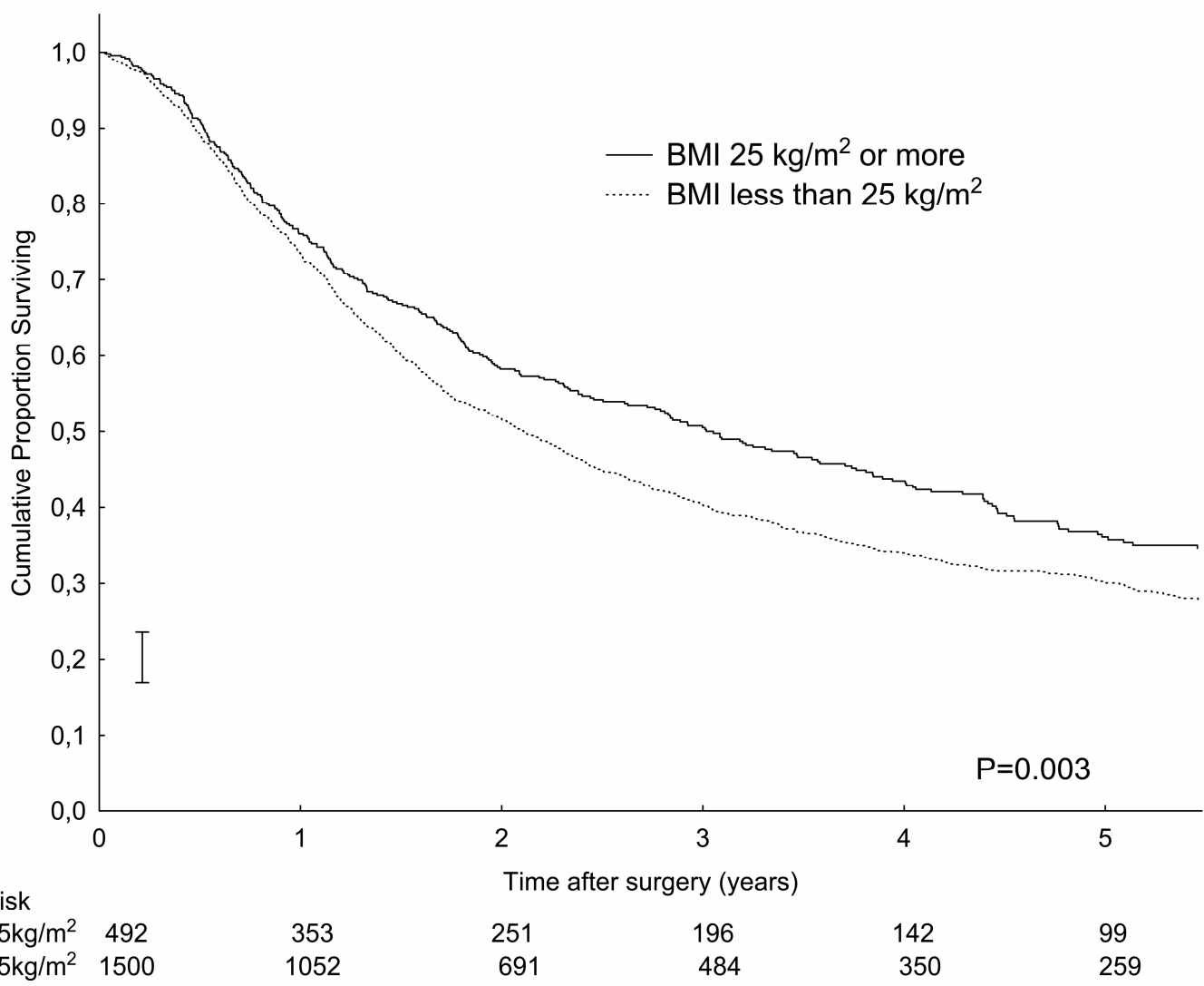




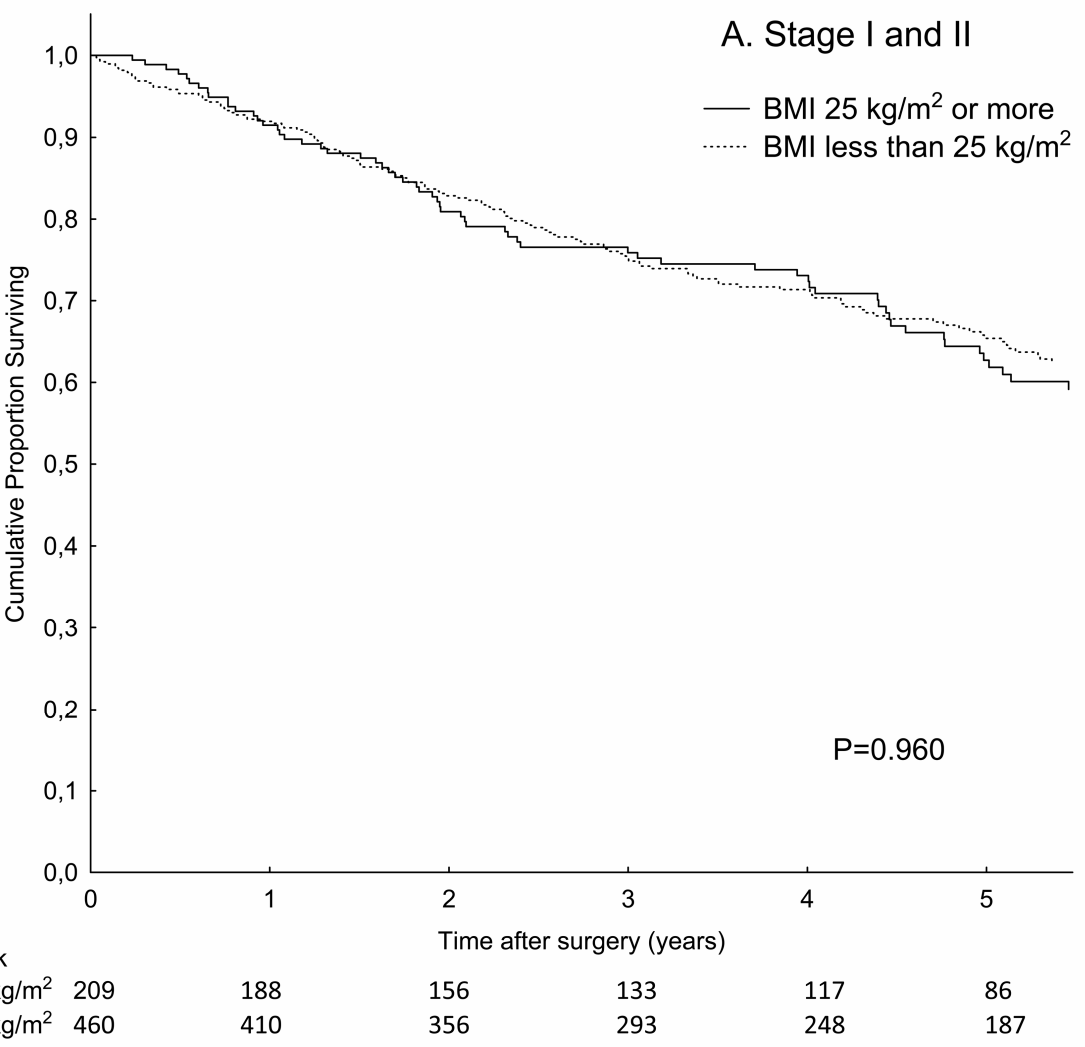

No. at risk BMI > 25kg/m² 209 $\mathrm{BMI}<25 \mathrm{~kg} / \mathrm{m}^{2} \quad 460$

410

356

248

187

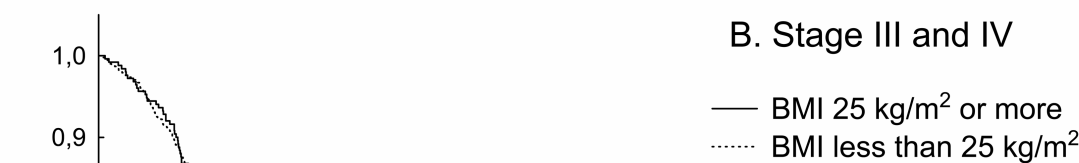

...... BMl less than $25 \mathrm{~kg} / \mathrm{m}^{2}$

No. at risk BMI $>25 \mathrm{~kg} / \mathrm{m}^{2} \quad 283$ BMI $<25 \mathrm{~kg} / \mathrm{m}^{2} \quad 1010$ 